governments is to win a war, and the new weapons imply such appalling destruction that no war can be won. But he points out that any ban on nuclear weapons alone would "obviously suit the Communists to engage in a war in which their enormous superiority in manpower and conventional armaments could hardly fail to be decisive". For the Western Powers to refuse ever to use the bomb first would ensure their defeat ; any uncertainty about its use might lead to another "drift into war". He then puts forward some very interesting arguments that the function of conventional armaments in this situation is as a "trip-wire" to ensure that any future aggression cannot gain its ends without having to face full-scale nuclear war and that, since no future global war can possibly last long, economies must be looked for in those applications required only for long-term hostilities.

The second author, Dr. R. L. Meier, sets out a series of propositions which he considers valid where "there are no important constraints upon how the major powers may act in the short run". The most important and most controversial are No. III, in which he argues for a sharp distinction between conventional weapons and nuelear weapons (Sir John Slessor separates "tactical" nuclear weapons from the H-bomb), and No. VI, that when superweapons have reached a certain level "it appears to be no longer possible to negotiate disarmament at the nuclear level" because "any nation which does not act, in good faith would be able to dictate terms to any part of the world, or annihilate it" since "the margin of error in detection and accounting is still enough to dominate". Back to good faith once more.

The third author, Mr. Hanson W. Baldwin, starts with an illuminating and balanced discussion of the new methods for delivering nuclear explosives, and points out that, while the power of the attack has so enormously increased the power of defence, interception has considerably decreased. He recommends that "we must be capable of fighting all-out nuclear war, a limited nuclear war, a major non-nuclear war, small scale brush-wars". This counsel of despair may perhaps be practicable for the United States with its immense resources; it could scarcely be so for Great Britain.

The fourth author, Mr. C. W. Sherwin, emphasizes a further point. That old-fashioned principle of war was to seek out and neutralize the armed forces of the enemy. But in a modern future war these armed forces will be small, light, mobile machines, which can be fairly easily protected against blast, while cities are large, immobile and from their construction very sensitive to blast. In other words, success is probably much easier by attacking civilian populations. This was once forbidden by a Geneva Convention; but such conventions again imply good faith. Mr. Sherwin proceeds by outlining a set of rules for nuclear strategy in a deterrent war ; even supposing these rules to be correct it is most unlikely that they could be followed in the mass hysteria of an atomic war. He concludes by hoping that, while the Mark I solution of peace-through-deterrence is perhaps not the ultimate means of preventing major war, it may give time for a final solution. Dr. Warren Amster concludes the discussion in a short article which emphasizes the points made by the previous authors.

This discussion is of the utmost interest, and can scarcely be summarized in so short a review. The discussion is being continued.

\section{RESEARCH COUNCIL OF ALBERTA}

\section{REPORT FOR 1955}

$\mathrm{T}$ HE thirty-sixth annual report of the Research Council of Alberta*, covering 1955, refers to increased emphasis of basic geological research and survey in view of its importance to much of the Province's resources. Besides the cil-sand area project, clay research, glacial geological studies and micropalæontological research carried over from 1954, further work undertaken included a ground-water survey of the Province, stratigraphical studies of the southern foothills, and a laboratory study on the chemical variation between marine and non-marine sediments. The Council's soil surveyors were again engaged principally in the Peace River district of Alberta; but the report refers also to other projects of the Alberta Soil Survey conducted mainly by Federal Survey staff, such as the field-work on the Edmonton map-sheet and irrigation research on solonetzic soils at Youngstown, in co-operation with the University of Alberta Department of Soil Science, the Canada Experimental Farms Service and the Provincial Department of Agriculture.

Encouraging progress has been made in the reorientated coal research programme. Investigations of the physical behaviour of coal in an ultrasonic field demonstrated that the 'true' density of coal appears to remain substantially unaffected, but that the surface area of the coal tends to increase with the frequency of vibration and time of exposure; preliminary carbonization tests have indicated that the presence of traces of nitric oxide in the retort can induce significant modifications in the nature of the tar. A combination of infra-red studies and elementary analysis has indicated the relation between humic acid and coals of various ranks, and studies of the oxidation of phenols to humic acid have shown that oxidative polymerization of aromatic substances can yield naphthenic structures known to occur in coal and petroleum. Polarographic studies indicate that humic acids from hydroquinone and low-rank coal have less condensed structures than humic acids from material of higher rank. The presence of a cracking catalyst such as alumina-siljeate in carbonization about $600^{\circ} \mathrm{C}$. appeared to affect the primary decomposition of the coal as well as the secondary decomposition of the primary tar.

The work of the Applied Research Laboratory was confined to attempts to surface-seal Albertan subbituminous coals against loss of water so as to prevent or reduce disintegration during storage. Some success was achieved with emulsions of wax or bitumen, and substantial progress was also made in a study of the grindability of coal.

Petroleum research has included studies of the kinetics of thermal degradation or maturation for the removal of vanadium or nickel from McMurray oil ; the work indicates that geological time has been too short to account for the observed maturation of crude oils in Alberta at the temperatures usually regarded as reasonable during geological time, and suggests that considerable importance must be attached to catalysis in the formation of crude oil. A survey has been undertaken of the carcinogenicity of crude oils of Western Canada ; detailed investigations of the sulphur content of heavy oils using

* Research Council of Alberta. Thirty-sixth Annual Report, 1955. (Report No. 73.) Pp. 52. (Edmonton: Research Councll of Alberta,
1956.) 
chromatography on the distillate fraction showed that extraction methods for removing sulphur from the oil-sands oil are unsatisfactory, and studies are being made of desulphurization by catalytic decomposition or oxidation.

Work on natural gas and its utilization was limited to three projects : the partial oxidation of $n$-butane; the production of carbon black; and the hightemperature pyrolysis of butane. Results in the first project indicate that the reaction is essentially that of the 'cold flame', characterized by a pronounced induction period, sharp reaction peak and selfquenching termination. Use of the permeable tube technique has permitted continuous production of carbon black from natural gas for up to four hours; but extensive semi-works tests are required before any economic evaluation of the process can be made. Preliminary results indicate higher partial pressures in the pyrolysis of butane favour formation of ethylene and lower pressures that of acetylene. Winter field trials of the injection of lignosol and lignosol-chromate mixtures to prevent frost-heaving in soils showed that the highly mechanized procedure was less efficient than anticipated and that the designed proportions of lignosol and chromate were not set up in the field as successfully as in the laboratory; a study of the electrosmosis of soils showed that addition of lignosol enabled the solution to move through coarse sands in which the process was ineffective in its absence.

The paucity of the cyclic animal populations continued throughout central and northern Alberta; but a careful census showed increases in selected locations, especially in the south-east of the Province. Measurements of solar ultra-violet radiation were continued. Work on the hatchability of turkey eggs demonstrated that the use of upstanding males in the breeding pens increased fertility compared with eggs from pens in which front-heavy males were used.

Some attention has been given by an ad hoc committee to the prevention of hail damage.

\section{RELATIVITY AND SPACE TRAVEL}

FTER the publication in Nature of April 28 of A communications on this subject by Prof. $H$. Dingle and Prof. W. H. McCrea, a number of letters were received by the Editors, some of them sup. porting Prof. Dingle's views and some Prof. McCrea's. Many were mathematical in character, whereas others developed the argument in general terms. It would have been impossible for reasons of space alone to print these letters in full ; it seemed to the Editors, therefore, that the best course was to collect the correspondence and to submit a copy of each letter to Prof. Dingle and to Prof. McCrea, who were then invited to prepare their concluding statements in the light of the letters received. This has been done, and the two statements are published below.

THE outstanding fact confirmed by this correspondence (in which I include letters received privately) is profoundly disquieting. In various ways we now actually deal with velocities at which the abnormal relativity phenomena become important, and in matters the gravity of which can scarcely be exaggerated and in which we must act on calculation alone, we are at the mercy of physicists, many of whom can believe that what can be thought away can have effects which cannot.

For obvious reasons, I reply only to correspondents who agree in (and only in) thinking me wrong. They comprise two classes: (a) those who hold that the accelerations are irrelevant and I have misread 'special' relativity; (b) those who regard the accelerations as important. (McCrea so regards them, but bewilderingly uses them only as a talisman to fecundate the otherwise sterile 'Lorentz contraction' during the uniform motion.)

It is difficult to understand the existence of class (a), since without the accelerations $M$ and $R$ are indistinguishable. A number 'refute' me by the phenomenon of mesons, the half-life and velocity of which imply that they have suffered a 'time dilatation'. I am astonished that this is thought relevant. The argument seems to be this: "Dingle says that the relativity anomalies are only imaginary: this one is observed : hence Dingle is wrong". What I say is not that these anomalies are "only imaginary", but that they occur only when at least one of the times involved refers to an absent clock and so must be determined by a conventional definition. This is so in the meson case, where effectively the starting time (conventional) is compared with the arrival time (observed); the 'time dilatation' must therefore be expected. In the space traveller problem, however, the clocks are directly compared; convention is eliminated and the anomalies disappear.

In reply to requests, I reluctantly indicate McCrea's error. He writes : "At the event $\left[E_{1}\right]$ of $M$ 's com. pleting the part of his outward journey performed with speed $V$, observer $R$ plots $M$ as at a distance $X$. . . Owing to the Lorentz contraction, $M$ at the same event plots $R$ as at distance $\alpha X$. . . It does not matter which observer regards himself as at rest". But $M$ observes another event, $E_{2}$, at which $R$ 's uniform travel ends, and McCrea later confirms that it is at $E_{2}$ that $R^{\prime}$ s distance is $\alpha X$. Hence he connects $R$ 's estimate for one pair of events $\left(E_{0}\right.$ and $E_{1}$, where $E_{0}$ is the event of $R$ and $M$ beginning their separation with velocity $V$ ) with $M$ 's for another $\left(E_{0}\right.$ and $\left.E_{2}\right)$ by the "Lorentz contraction", which is clearly wrong. But I repeat that the error of the conclusion should be obvious without this.

A complete solution of the space traveller problem on the basis of special relativity, showing how the anomalies cancel out, will be published by the Physical Society.

Now for the accelerations. General relativity asserts that all motion is relative (that is, all coordinate systems are equivalent). It has convineingly formulated this principle only for gravitational motions; but, if it is true, no acceleration affects a clock. Some think this inconsistent with the displacement of spectrum lines in a gravitational field, but that is caused by the field, not acceleration. If the stellar atoms are stationary it is still required.

We do not know what effect other causes of acceleration may have. Hence, since our traveller will certainly not be ejected by gravitation, we cannot state the effect, if any, of the means employed. But, by hypothesis, the process is too briof for appreciable slowing down.

The only escape is by supposing, as some do, that the initial acceleration causes a change of rate which persists when the motion becomes uniform. This is arbitrary, and to justify McCrea's formula the change would astonishingly have to be exactly equal to the 